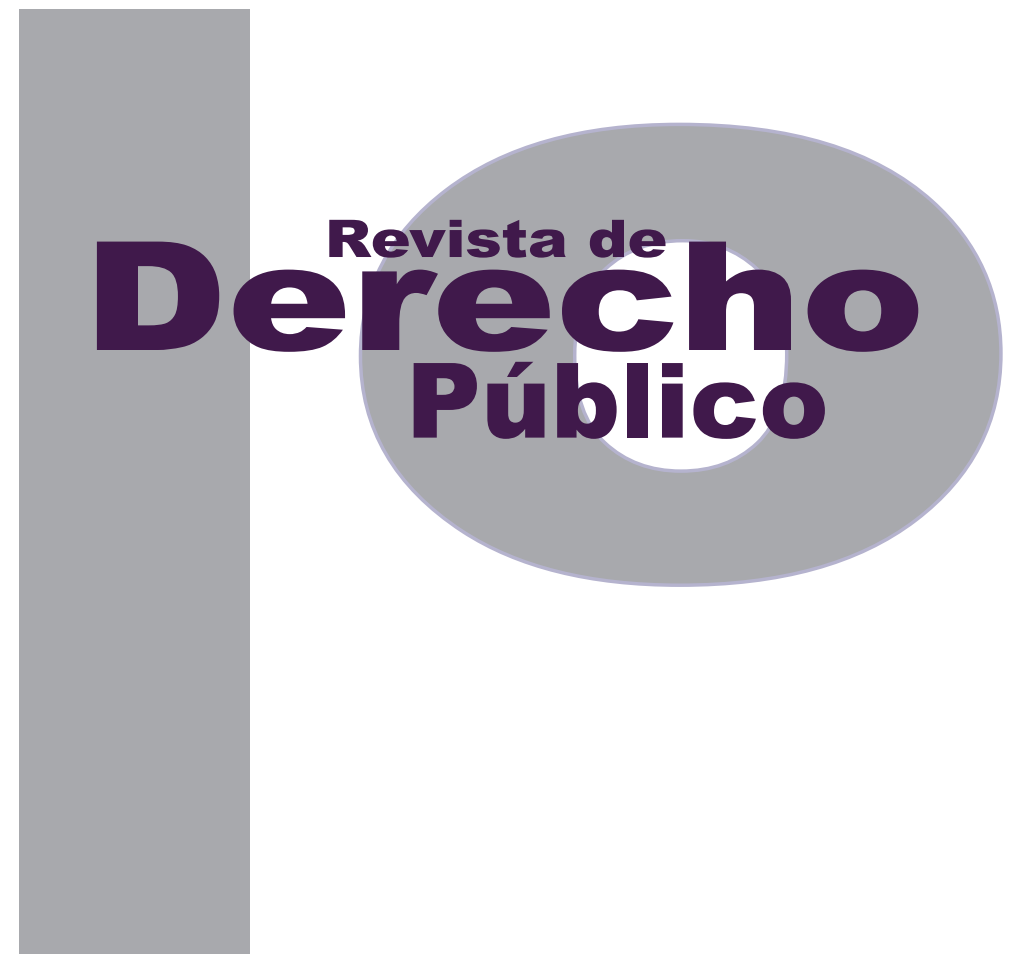

\title{
AVANCES Y RETROCESOS NORMATIVOS EN MATERIA DEL DERECHO A LA SALUD DE LOS JÓVENES TRABAJADORES EN Colombia
}

\author{
LAURA Viviana Jaimes Pedraza
}

Revisión de tema

DOI: http://dx.doi.org/10.15425/redepub.34.2015.16

Universidad de los Andes

Facultad de Derecho

Revista de Derecho Público N. ${ }^{\circ} 34$

Enero - Junio de 2015. ISSN 1909-7778 


\title{
Avances y retrocesos normativos en materia del derecho a la salud de los jóvenes trabajadores en Colombia
}

\section{Resumen}

Cuando se trata de trabajo infantil, es importante mencionar que en este califica toda actividad desarrollada por una persona menor de 18 años, encaminada a la producción, comercialización, transformación, venta o distribución de bienes o servicios. Este artículo explora la normativa sobre trabajo infantil tanto colombiana como la existente en el marco internacional. El campo de interés está centrado en el derecho a la salud de los jóvenes trabajadores, en el cual se busca comparar la legislación nacional con la normativa internacional existente sobre el tema para hacer una reflexión y determinar cómo está Colombia en esta materia y qué falta por hacer para lograr la protección efectiva de dicho derecho. La investigación realizada indica que la normativa colombiana en materia de salud, a pesar de plantearse como garantista, no es suficiente para cumplir con los estándares internacionales, y que hace falta reglamentación para llegar a satisfacer todos los compromisos internacionales adquiridos.

Palabras clave: trabajo infantil, salud, derechos de los niños, oाт, joven trabajador.

\section{Regulatory developments and setbacks in the right to health of young workers in Colombia.}

\begin{abstract}
When it comes to child labor, it is important to mention that it is considered as any activity performed by a person under 18 years aimed the production, marketing, processing, sale or distribution of goods or services. This article explores both the Colombian legislation on child labor, and the rules in the International context. The area of interest is focused on the right to health of young workers, the article seeks to compare national legislation with international rules on the subject to reflect and determine how it is Colombia on this issue and what remains to be done to achieve effective protection of that right. The text indicates that the Colombian legislation on health, in spite of being considered as guarantor, is not enough to meet international standards, and regulations need to be able to satisfy all the international commitments.
\end{abstract}

Key words: Child labor, Health, Children's Rights, ıLo, Young Worker.

\section{Avanços e retrocessos normativos em matéria de direito à saúde dos jovens trabalhadores na Colômbia}

\section{Resumo}

Quando se trata de trabalho infantil, é importante mencionar que neste se qualifica toda atividade desenvolvida por uma pessoa menor de 18 anos, encaminhada à produção, comercialização, transformação, venda ou distribuição de bens ou serviços. Este artigo explora a normativa sobre o trabalho infantil tanto colombiana quanto a existente no marco internacional. 0 campo de interesse está centrado no direito à saúde dos jovens trabalhadores, no qual se busca comparar a legislação nacional com a normativa internacional existente sobre o tema para fazer uma reflexão e determinar como a Colômbia está nesta matéria e o que falta ser feito para conseguir a proteção efetiva de dito direito. A pesquisa realizada indica que a normativa colombiana em matéria de saúde, apesar de apresentar-se como garantista, não é suficiente para cumprir com os padrões internacionais, e que faz falta uma regulamentação para chegar a satisfazer todos os compromissos internacionais adquiridos.

Palavras-chave: trabalho infantil, saúde, direitos das crianças, oІт, jovem trabalhador. 


\title{
Avances y retrocesos normativos en materia del derecho a la salud de los jóvenes trabajadores en Colombia*
}

\author{
Laura Viviana Jaimes Pedraza*
}

\section{SUMARIO}

Introducción - I. PROBLEMÁTICA DEL TRABAJO INFANTIL - A. En Colombia - B. Internacional - II. NORMAS EN MATERIA DEL DERECHO A LA SALUD - A. Normas generales sobre salud en Colombia - B. Normas relativas a la especial protección de los jóvenes trabajadores en Colombia - C. Normas en el marco internacional - III. REFLEXIÓN SOBRE LEGISLACIÓN NACIONAL Y SU COMPARACIÓN CON EL MARCO INTERNACIONAL - IV. CONCLUSIONES - Referencias.

Cómo citar este artículo: Jaimes Pedraza, L. V. (Junio, 2015). Avances y retrocesos normativos en materia del derecho a la salud de los jóvenes trabajadores en Colombia. Revista de Derecho Público, 34. Universidad de los Andes (Colombia).

** Estudiante de décimo semestre de Jurisprudencia en la Universidad del Rosario. Correo: jaimes.laura@urosario.edu.co 


\section{Introducción}

El trabajo infantil es un fenómeno que preocupa a la sociedad actual pues se considera un impedimento para que las niñas, los niños y los jóvenes tengan acceso a la educación y a la recreación, y puede tener repercusiones negativas en la salud de los menores (Pedraza y Ribero, 2006, pág. 4).

Colombia no es ajena a la preocupación mundial frente al trabajo infanto-juvenil por las consecuencias negativas que puede ocasionar en el bienestar de los menores. El país ha reaccionado normativamente tanto en el ordenamiento interno (Constitución Política y diferentes reglamentaciones nacionales y regionales) como en la adopción de los convenios de la Organización Internacional del Trabajo (oıт) en lo que respecta a la edad mínima para trabajar y a la definición de las peores formas de trabajo infantil (Pedraza y Ribero, 2006, pág. 8).

En este artículo se pretende hacer una reflexión sobre los avances y retrocesos de la legislación colombiana en el tema que se aborda, respecto a la normativa internacional. Para este propósito, se hará una breve contextualización del fenómeno del trabajo infantil en Colombia y en el mundo. Posteriormente, se expondrá una compilación de normas que traten el derecho a la salud de los jóvenes trabajadores, primero en un barrido por las normas nacionales y luego por la normativa internacional. Finalmente, soportada en toda la normativa compilada, se compararán las normas vigentes en el orden jurídico colombiano con las normas internaciona- les, para determinar en qué medida Colombia cumple con los compromisos adquiridos y qué falta por hacer en esa materia.

\section{PROBLEMÁTICA DEL TRABAJO INFANTIL}

El Instituto Colombiano de Bienestar Familiar (ICBF) define el trabajo infantil "como toda actividad física o mental, remunerada o no, dedicada a la producción, comercialización, transformación, venta o distribución de bienes o servicios, realizada por personas menores de 18 años, en forma independiente o al servicio de otra persona natural o jurídica" (ICBF, 2013, pág. 1).

El trabajo infantil supone riesgos para los niños y las niñas, especialmente aquellas actividades catalogadas por la oाт como peores formas, dentro de las que se encuentran la esclavitud, la trata; la explotación sexual o pornografía; el reclutamiento, actividades ilícitas como tráfico de estupefacientes y cualquier otro trabajo que dañe la salud, la seguridad o la moralidad de los niños y las niñas (ICBF, 2013, pág. 2).

El trabajo infantil se presenta en muchos países, y debido a la importancia que tiene la protección de los niños a nivel mundial se ha ahondado en los esfuerzos para combatir esta problemática. En esta primera parte del artículo se hará un breve barrido por algunas generalidades que involucra el trabajo infantil tanto en Colombia como internacionalmente. 


\section{A. En Colombia}

Según la Encuesta Nacional de Trabajo Infantil 2011 realizada por el Departamento Administrativo Nacional de Estadística (DANE), para ese año en Colombia había 1465000 niños, niñas y adolescentes entre 5 y 17 años trabajando. De ellos, el $51.6 \%$ no recibía remuneración, $28.3 \%$ era asalariado y $20 \%$ trabajó como independiente.

En el año 2012, de acuerdo con la Gran Encuesta Integrada de Hogares, Módulo Trabajo Infantil del DANE, de un total de 11332000 de población de 5 a 17 años, 1111000 se encontraban trabajando (ICBF, 2013, pág. 1). Según la misma encuesta los sectores económicos en los que más se presenta el trabajo infantil son el comercio, la industria manufacturera y la agricultura; y las ciudades con mayor tasa son Ibagué, Bucaramanga, Sincelejo, Bogotá y Quibdó.

En el trimestre octubre-diciembre de 2013, según el DANE (2014. págs. 2-5) la tasa de trabajo infantil fue $9,7 \%$, "inferior en 0,5 puntos porcentuales frente a la tasa reportada en el mismo periodo de 2012". En el total nacional, la población infantil de 5 a 17 años que trabaja disminuyó en 83000 personas frente al mismo trimestre de 2012. “En las cabeceras la disminución fue de 123 mil personas, mientras que en resto se incrementó en 40 mil personas".

Estas estadísticas dejan ver que los esfuerzos que se han hecho en el país para combatir el trabajo infantil no son suficientes, pues la tasa es aún muy alta -actualmente hay más de un millón de menores que trabajan-, y la mayoría de quienes trabajan no tienen ni la edad permitida, ni lo hacen dentro de las formalidades que exige la ley.

En Colombia, de acuerdo con el artículo 114 de la Ley 1098 de 2006, no está permitido que ningún menor de edad trabaje en actividades que involucren acciones peligrosas, insalubres o que requieran grandes esfuerzos. Legalmente los menores pueden trabajar en jornadas establecidas dependiendo de la edad, con un máximo de 8 horas diarias y 48 semanales para los jóvenes de 16 a 18 años de edad.

Por lo general los menores trabajadores se desenvuelven en ambientes laborales que los exponen a factores de alto riesgo, herramientas no aptas y esfuerzo excesivo, esto hace que se asocie el trabajo infantil con incidencias negativas sobre su salud tanto en el corto como en el largo plazo (Pedraza y Ribero, 2006, pág. 8). Dentro de los efectos del trabajo infantil, se encuentran la vulneración a derechos como la educación, la salud y la recreación, el aumento de la deserción escolar y la limitación de otros derechos y libertades (ICBF, 2013, pág. 7).

De acuerdo con el estudio de O'Donnell, Rosati y van Doorslaer (2005, págs. 1-31) sobre los efectos en la salud futura de los menores que ingresan a una edad temprana al mercado laboral, quienes han trabajado siendo muy jóvenes presentan niveles de salud más precarios en su edad adulta. La dificultad de las tareas y las duras condiciones de trabajo crean un gran número de problemas, como el envejecimiento 
prematuro, la desnutrición, la depresión o la drogadicción.

En la adolescencia (15-17 años), el problema puede ser que algunos jóvenes que ya están fuera del sistema educativo porque trabajan desde edades tempranas - trabajo infantil- inician su juventud con serias dificultades para acceder a una trayectoria laboral y social positiva (ort, 2010, pág. 14). De ahí que se consideran políticas en favor del trabajo decente todas aquellas que se promuevan en este campo con el fin de solucionar los problemas existentes en este segmento de la población.

\section{B. Internacional}

Hoy en día cerca de 168 millones de niños trabajan en el mundo, una cifra que ronda el $11 \%$ del conjunto de la población infantil. Los niños en trabajo peligroso ascienden a 85 millones, es decir, más de la mitad de todos los niños en situación de trabajo infantil. La explotación infantil existe en todos los continentes y adopta varias formas de acuerdo con las culturas y tradiciones de la región. La región de Asia y el Pacífico tiene el mayor número de niños en situación de trabajo infantil en el grupo de 5 a 17 años: casi 77,7 millones. En África Subsahariana se registran 59,0 millones de niños en situación de trabajo infantil, en América Latina y el Caribe 12,5 millones y 9,2 millones en Oriente Medio y África del Norte (oIt, 2013, págs. 7-11).

En el mundo hay muchos jóvenes que se encuentran laborando en trabajos de baja productividad o temporales que no están a la altura de sus expectativas. En países desarrollados los jóvenes son contratados en empleos atípicos y la transición de estos al trabajo decente sigue siendo postergada. En países en desarrollo, los jóvenes encuentran fuertes barreras a la hora de buscar trabajo, una gran población suele trabajar en el hogar sin ningún tipo de remuneración, es decir, están en el sector informal (oıт, 2012, pág. 4).

\section{NORMAS EN MATERIA DEL DERECHO A LA SALUD}

\section{A. Normas generales sobre salud en Colombia}

El derecho a la salud está contemplado en el artículo 49 de la Constitución como un derecho económico, social y cultural, cuya atención por ser un servicio público está a cargo del Estado, e incluye su promoción, protección y recuperación. En este sentido, es obligación del Estado incluir los principios de eficiencia, universalidad y solidaridad en la organización y reglamentación de la prestación de los servicios de salud y saneamiento ambiental.

Se garantiza entonces, desde el mandato constitucional, el acceso para todas las personas a un servicio que cubra desde la promoción hasta la recuperación de la salud. Adicionalmente, el constituyente establece cuáles son los principios bajo los cuales se debe guiar la prestación del servicio de salud, sea por entidades públicas o por privadas. 
A pesar de no haber sido consagrado como un derecho fundamental en la Carta Magna, la Corte Constitucional en sentencia T-760 de 2008 reiteró su posición al exponer el carácter del derecho a la salud, manifestando que este es fundamental de manera autónoma cuando se concrete una garantía subjetiva derivada de las normas que rigen el derecho a la salud, y que el acceso a un servicio de salud que se requiera y esté contemplado en los planes obligatorios es derecho fundamental autónomo.

Dentro del marco del mandato constitucional se dicta la Ley 100 de 1993, por la cual se crea el sistema de seguridad social integral. Esta ley en su artículo $2^{\circ}$ establece que "El servicio público esencial de seguridad social se prestará con sujeción a los principios de eficiencia, universalidad, solidaridad, integralidad, unidad y participación". El principio de universalidad hace referencia a "la garantía de la protección para todas las personas, sin ninguna discriminación, en todas las etapas de la vida".

En Colombia hay dos formas de afiliarse al sistema de salud: el régimen contributivo al que pertenecen las personas vinculadas laboralmente, y el régimen subsidiado al cual está afiliada la población de menores ingresos y sin capacidad de pago del servicio de salud. De acuerdo con el artículo 9 del Decreto Reglamentario 692 de 1994, deben afiliarse al régimen contributivo de manera obligatoria todas aquellas personas nacionales o extranjeras residentes en Colombia, vinculadas mediante contrato de trabajo que se rija por las normas colombianas.
Según el artículo 28 del Decreto 806 de 1998 el régimen contributivo, al cual deberían pertenecer todos los jóvenes trabajadores por encontrarse vinculados mediante un contrato de trabajo, garantiza a los afiliados los siguientes beneficios:

a. La prestación de los servicios de salud incluidos en el Plan Obligatorio de Salud (Pos).

b. El subsidio en dinero en caso de incapacidad temporal derivada por enfermedad o accidente.

c. El subsidio en dinero en caso de licencia de maternidad.

Es importante tener en cuenta la forma en que se realizan los aportes al sistema de salud en el régimen contributivo. La cotización por salud,

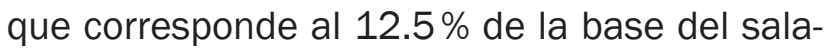
rio de la persona, se hace en conjunto con el empleador, este aporta el $8.5 \%$ y el empleado el $4 \%$, suma que se le debe descontar del total devengado.

El aporte de salud es responsabilidad de la empresa, pues es el empleador quien debe pagar mensualmente tanto el valor del $8.5 \%$ que le corresponde a él como el del $4 \%$ que le descuenta al empleado. Ningún empleador del sector privado o del sector público está exento del pago de las cotizaciones. Si el empleador no afilia a sus empleados o no paga oportunamente los aportes deberá cubrir en su totalidad la atención de los accidentes de trabajo, así como los riesgos y eventualidades por enfermedad general y maternidad. 
En el Código Sustantivo del Trabajo se encuentra lo relativo a la licencia de maternidad. El artículo 236 establece que toda trabajadora en estado de embarazo tiene derecho a una licencia remunerada de catorce semanas en la época de parto, y que la licencia de maternidad para madres de niños prematuros tendrá en cuenta la diferencia entre la fecha gestacional y el nacimiento a término, la cual será sumada a las 14 semanas. Adicionalmente, de las catorce semanas de licencia remunerada, la semana anterior al probable parto será de obligatorio goce.

Este Código incluye, en su capítulo V, reglas sobre la licencia que se da para la lactancia y todos los demás aspectos que tienen relación con el tema de la maternidad y el tratamiento que debe tener la madre cuando trabaja.

De todo lo anterior es posible concluir que el derecho a la salud es un derecho fundamental autónomo que debe garantizarse a todas las personas, lo que implica para el Estado ciertas obligaciones. Por otro lado, en general, las normas que regulan el derecho a la salud de los trabajadores les son aplicables a los jóvenes que laboran, es decir, en ningún caso se podrá desconocer a un menor de edad que trabaje alguna de estas garantías mínimas, empezando por vincularlo al régimen contributivo.

\section{B. Normas relativas a la especial protección de los jóvenes trabajadores en Colombia}

En el artículo 44 de la Constitución Política de Colombia se encuentran los derechos funda- mentales de los niños, y entre ellos figuran la vida, la integridad física, la salud y la seguridad social. El mandato constitucional agrega que los derechos de los niños prevalecen frente a los de los demás y que deben ser protegidos contra toda forma de abandono, violencia física o moral, secuestro, venta, abuso sexual, explotación laboral o económica y trabajos riesgosos.

La Constitución es norma de normas y por tanto todas las autoridades deben en sus actuaciones ceñirse a lo que en ella está establecido, atendiendo lo dispuesto en su artículo 4. Los principios constitucionales deben aplicarse indistintamente al interpretar las leyes, y en el caso particular de aquellas relacionadas con el trabajo infantil deben estar encaminadas a lograr la protección efectiva de todos los derechos fundamentales de los niños.

Posteriormente, en virtud de la protección constitucional a los menores y de los convenios de la oIt ratificados por Colombia, se expide el Código de la Infancia y la Adolescencia (Ley 1098 de 2006). Mediante esta ley, tal como se afirma en el artículo 2, se establecen normas para la protección integral de los niños, las niñas y los adolescentes, tendientes a garantizar el ejercicio de sus derechos y libertades, así como las estipulaciones más relevantes sobre el trabajo de jóvenes menores de edad.

Hay un interés superior por los niños, niñas y adolescentes, en virtud del cual se obliga a todas las personas a garantizar la satisfacción integral y simultánea de todos sus derechos humanos, que son universales, prevalentes e interdepen- 
dientes. Dicha prevalencia aplica frente a toda medida, acto o decisión que deba adoptarse, en especial cuando exista un conflicto entre sus derechos fundamentales y los de otra persona.

Al tenor del artículo 20, los niños, las niñas y los adolescentes serán protegidos, entre otros, contra la explotación económica y el uso en la mendicidad por parte de cualquier persona, y contra la violación, la prostitución, la explotación sexual, la pornografía y en general cualquier conducta que atente contra la integridad y formación sexual del menor de edad. Adicionalmente, este artículo en su numeral 12 hace referencia a la protección contra el trabajo que pueda afectar la salud, la seguridad y la integridad del menor o que impida su acceso al derecho a la educación; mientras que en el numeral 13 incluye la protección contra las peores formas de trabajo contenidas en el Convenio 182 de la olt.

En cumplimiento del principio de corresponsabilidad, que consiste en el deber que se comparte entre la familia, la sociedad y el Estado respecto a adelantar las acciones conducentes a garantizar el ejercicio de los derechos de los niños, las niñas y los adolescentes, el artículo 40 impone a las asociaciones, las empresas y el comercio organizado en general, la obligación de tomar parte activa en el logro de la vigencia efectiva de los derechos y garantías de esta población.

El inspector de trabajo es quien está facultado para expedir, por escrito, la autorización para que un adolescente pueda trabajar. Esta debe ser solicitada por los padres, el representante legal o el defensor de familia, y para obtenerla, entre otros requisitos, el empleador debe contar con un certificado del estado de salud del adolescente trabajador.

El artículo 117 establece que ninguna persona menor de 18 años puede ser empleada o realizar trabajos que impliquen peligro o que sean nocivos para su salud e integridad física o psicológica o los considerados como peores formas de trabajo infantil.

Según el artículo 114 la jornada laboral de los adolescentes entre 15 y 17 años tendrá una duración máxima de siete horas diarias y treinta horas a la semana, y hasta las 6:00 de la tarde. Para los mayores de 17 años la jornada máxima es de ocho horas y cuarenta horas semanales, y hasta las 8:00 de la noche.

Acorde con el artículo 116, en el que es posible encontrar un enfoque de género, la jornada laboral de la adolescente mayor de 15 y menor de 18 años que se encuentre en estado de embarazo no puede exceder de cuatro horas diarias a partir del séptimo mes de gestación y durante la lactancia, sin disminución de su salario y prestaciones sociales. Esto, sin perjuicio de los derechos contenidos en el Código Sustantivo del Trabajo.

Este artículo toma especial relevancia teniendo en cuenta que en Colombia, tal como lo afirma la directora del Instituto Colombiano de Bienestar Familiar, "según el Observatorio del Bienestar de la Niñez del ICBF y de acuerdo con las estadísticas de nacimientos del DANE, desde el año 2008 has- 
ta el 2013, han nacido cada año, en promedio, 159.656 niñas y niños, de madres entre 10 y 19 años" (ICBF, 2014).

La Resolución 1677 de 16 de mayo de 2008 del Ministerio de Trabajo, conforme con el artículo $4^{\circ}$ del Convenio 182 de la oाт "que exige a los países definir mediante listas lo que se considera trabajo infantil que, por su naturaleza o por las condiciones en las que se realiza, probablemente atenta contra la salud, la seguridad o la moralidad de los niños y niñas" establece específicamente sector por sector las actividades en las que ningún niño, niña o adolescente menor de 18 años de edad puede trabajar.

Finalmente, en materia jurisprudencial la Corte Constitucional ha emitido numerosos pronunciamientos sobre el derecho a la salud de los niños, niñas y adolescentes, sin referirse en ninguna ocasión al caso particular de los jóvenes trabajadores. A continuación se explican algunos de los más relevantes.

En la sentencia T-133 de 2013 estableció que los niños y las niñas, por encontrarse en condición de debilidad, merecen mayor protección; que sus derechos, entre ellos la salud, tienen un carácter prevalente en caso de que se presenten conflictos con otros intereses. Cuando se vislumbre la vulneración o amenaza de este derecho, el juez constitucional debe exigir su protección inmediata y prioritaria por parte de todas las autoridades públicas.

En la sentencia T-036 de 2013 dispuso que cuando la falta de suministro del servicio médi- co afecta los derechos a la salud, a la integridad física y a la vida de los niños y las niñas, "se deberán modular o inaplicar las disposiciones que restrinjan el acceso a los servicios que requieren, teniendo en cuenta que tales normas de rango inferior impiden el goce efectivo de sus garantías Superiores".

Y en la sentencia T-218 de 2013 manifiesta que la garantía efectiva del derecho a la salud de los niños y las niñas no solo se materializa en la prestación efectiva de un servicio o tratamiento médico que se necesite, sino que depende también del acceso al servicio público de salud, es decir, de la afiliación al Sistema General de Seguridad Social en Salud.

El derecho a la salud de un menor puede considerarse vulnerado, sin importar que no exista una patología qué tratar, por el hecho de no encontrarse incluido en un sistema que le permita contar en forma oportuna con los servicios de salud frente a cualquier enfermedad que pueda presentarse, pues "constituye en sí misma una vulneración no solo del derecho a la seguridad social, sino que afecta el derecho a la salud, a la integridad física y a la vida de los niños y las niñas" (CConst., T-218/2013).

Estos pronunciamientos jurisprudenciales son importantes en la medida en que incorporan dentro del derecho a la salud de los menores no solo la atención en caso de encontrarse enfermos, sino la obligación de estar afiliados a un sistema de seguridad social, que en consonancia con las normas laborales refuerzan la obligación del empleador de tener a sus trabajado- 
res, en especial a aquellos que sean menores de edad, cubiertos ante eventualidades de este orden.

\section{Normas en el marco internacional}

En primer lugar es importante resaltar la falta de un tratamiento especial al tema del derecho a la salud del joven trabajador. Según estudios de la oІт, en la mayoría de los casos lo que los países hacen es aplicar las leyes generales, pero no las normas especiales de infancia y adolescencia. Incluso se ha llegado a determinar que muy pocas veces se tienen en cuenta los convenios de la oIT, y que aun estando enunciados, no tienen incidencia en la decisión de fondo (oIT, 2006, pág. 11).

En segundo lugar, nos encontramos con que el derecho a la salud, si bien se encuentra definido en los instrumentos del Sistema Interamericano, no pueden ser exigido a través del mecanismo de petición individual que contempla la Convención Americana sobre Derechos Humanos (Fuentes Alcedo, 2006, pág. 11).

La Declaración Universal de los Derechos Humanos $^{1}$ en su artículo 25.1 protege el derecho a la salud, al decir que toda persona tiene derecho a un nivel de vida adecuado en el que se le asegure a él y a su familia la salud, el vestido, la vivienda, la asistencia médica, los servicios sociales necesarios y en especial la alimentación. Asimismo, en caso de desempleo, enfermedad,

$1 \quad$ Adoptada por la Asamblea General de la Organización de las Naciones Unidas mediante la Resolución 217 A (III) del 10 de diciembre de 1948. invalidez, viudez, vejez y otros casos de pérdida de sus medios de subsistencia por circunstancias independientes de su voluntad, se le debe garantizar un derecho a seguros que cubran estas contingencias.

El Pacto de Derechos Económicos, Sociales y Culturales, $^{2}$ (en adelante Pacto DESc), en su artículo 12 dispone que los Estados partes reconocen el derecho de todas las personas a disfrutar del nivel más alto posible de salud física y mental, e incluye algunas medidas que los Estados deben adoptar para asegurar la efectividad del derecho a la salud, entre ellas la reducción de la mortalidad infantil, el sano desarrollo de los niños, el mejoramiento de la higiene del trabajo y la creación de condiciones que aseguren a todos la asistencia médica.

Es posible apreciar que, aunque la articulación de las obligaciones de los Estados partes en el Pacto DESC y en el Protocolo de San Salvador difiere, la definición del derecho a la salud coincide en que este derecho implica que se garantice a las personas obtener el más alto nivel de disfrute de salud tanto física como mental.

El Comité DESc es el “órgano de supervisión del Pacto y está encargado de vigilar el cumplimiento de sus disposiciones y de asegurar la correcta interpretación de cada una de ellas" (Procuraduría General de la Nación, 2008, pág. 32-33). Su labor la realiza examinando los informes que le presenta cada uno de los Estados parte, y me-

\footnotetext{
2 Aprobado por la Asamblea General de la Organización de las Naciones Unidas mediante la Resolución 2200 A (XXI) del 16 de diciembre de 1966, y por Colombia mediante la Ley 74 de 1968.
} 
diante recomendaciones y observaciones generales explica el contenido y alcance de cada uno de los derechos contenidos en el Pacto.

En ejercicio de sus funciones, el Comité DESC emitió la Observación General $14^{3}$ en la que establece en el párrafo 12 que el derecho a la salud abarca los siguientes elementos, cuya aplicación dependerá de las condiciones que sobresalen en cada Estado Parte:

1. La disponibilidad, referida a que el Estado cuente con un número suficiente tanto de establecimientos, bienes y centros de atención de la salud, como de programas.

2. La accesibilidad a los establecimientos, bienes y servicios de salud debe ser para todos, sin discriminación alguna, dentro de la jurisdicción del Estado Parte. Este elemento incluye la no discriminación, la accesibilidad física, la accesibilidad económica o asequibilidad y el acceso a la información.

3. La aceptabilidad, que implica que los establecimientos, bienes y servicios de salud deben ser respetuosos de la ética médica y culturalmente apropiados, es decir respetuosos de la cultura de las personas.

4. La calidad, que exige que los establecimientos, bienes y servicios de salud además de ser aceptables desde el punto de vista cultural deben ser también apropiados desde el punto de vista científico y médico.

3 El derecho al disfrute del más alto nivel posible de salud (artículo 12 del Pacto Internacional de Derechos Económicos, Sociales y Culturales), $22^{\circ}$ período de sesiones, 2000.

Esta Observación General interpreta el Pacto DESC y explica en detalle en qué consisten los deberes de respetar, proteger, cumplir-proveer, cumplir-promover y cumplir-facilitar, y señala las obligaciones básicas que conlleva el derecho a la salud. Hay puntos comunes y diferencias entre el Pacto DEsc y la Observación General, que se deben en gran parte a las cuatro décadas que transcurrieron entre ambos documentos.

Hay ciertas obligaciones que no se encuentran en el Protocolo de San Salvador, y algunas están contempladas en otros derechos (Fuentes Alcedo, 2006, pág. 18).

En el Protocolo Adicional a la Convención Americana sobre Derechos Humanos en materia de Derechos Económicos, Sociales y Culturales, ${ }^{4}$ "Protocolo de San Salvador", es el artículo 10 el que trata el derecho a la salud y establece que "toda persona tiene derecho a la salud, entendida como el disfrute del más alto nivel de bienestar físico, mental y social". Destaca la obligación que surge para los Estados partes de reconocer la salud como un bien público y de adoptar ciertas medidas para garantizar este derecho, como lo son: la atención primaria de la salud a todos los individuos sujetos a la jurisdicción del Estado, la inmunización contra las principales enfermedades infecciosas, la prevención y tratamiento de enfermedades endémicas y profesionales, la educación de la población sobre la prevención y tratamiento de los problemas de

\footnotetext{
$4 \quad$ Adoptado por la Asamblea General de la Organización de los Estados Americanos, en el Décimo Octavo período ordinario de sesiones, en San Salvador. El Salvador, 17 de noviembre de 1988. Entrada en vigor: 16 de noviembre de 1999.
} 
salud, y la satisfacción de las necesidades de salud de los grupos de más alto riesgo y de las personas que por sus condiciones de pobreza son más vulnerables.

Tenemos entonces que lo establecido en el Protocolo de San Salvador no corresponde a un derecho a gozar de buena salud o de no estar enfermo, sino que se trata de un derecho a la protección de la salud, o un derecho a tener los medios que proporcionen el mayor nivel de bienestar posible (Fuentes Alcedo, 2006, pág. 14).

Es importante tener en cuenta que tal como lo establece el artículo 26 de la Convención Americana de Derechos Humanos, en materia de derechos económicos, sociales y culturales, los Estados partes se comprometen a adoptar tanto a nivel interno como mediante la cooperación internacional técnica y económica, providencias para lograr de manera progresiva la plena efectividad de los derechos que se derivan de las normas económicas, sociales y sobre educación, ciencia y cultura.

En el mismo sentido, la Observación General 14 del Comité DEsc (2000) establece que la realización progresiva del derecho a la salud no se puede interpretar como una privación del contenido significativo de las obligaciones de los Estados partes, por el contrario, implica la obligación concreta y constante de avanzar lo más rápido y eficazmente hacia la plena realización del derecho a la salud. Es decir, que aun cuando el Pacto establece la aplicación progresiva y reconoce los obstáculos que significa la falta de recursos, impone a los Estados obligaciones de efecto inmediato como la garantía de que ese derecho podrá ser ejercido por las personas sin discriminación alguna.

Quiere decir lo anterior que el concepto de progresividad de los derechos económicos, sociales y culturales no es una excusa para que los Estados omitan las obligaciones adquiridas tanto en el Pacto DESc como en el artículo 26 de la Convención Americana de Derechos Humanos y en el Protocolo de San Salvador. Significa, entonces, que a través del concepto de progresividad se impone a los Estados la obligación de tomar todas las medidas necesarias para lograr la plena efectividad de estos derechos en el menor tiempo posible.

Por su parte, tanto la Declaración Americana de Derechos y Deberes del Hombre ${ }^{5}$ como las Disposiciones Sociales de la Carta de la Organización de Estados Americanos en su artículo 11 enumera obligaciones referentes al derecho a la salud, las cuales establecen que toda persona tiene derecho a que su salud sea preservada según el nivel que permitan los recursos públicos. Las medidas relativas a la preservación del derecho son: la alimentación, el vestido, la vivienda y la asistencia médica.

Se tiene también la Declaración de los Derechos del Niño ${ }^{6}$ que en el artículo 4 dispone que estos deben gozar de seguridad social y tienen derecho a crecer y desarrollarse con buena sa-

5 Aprobada en la Novena Conferencia Internacional Americana. Bogotá, Colombia, 1948.

6 Aprobada por la Asamblea General de las Naciones Unidas mediante Resolución 1386 (XIV) del 20 de noviembre de 1959. 
lud. Para esto debe proporcionarse tanto al niño como a su madre, cuidados especiales tales como la atención prenatal y postnatal. Según este mismo artículo un niño tiene derecho a disfrutar de alimentación, vivienda, recreo y servicios médicos adecuados.

La Convención sobre los Derechos del Niño ${ }^{7}$ en el artículo 24 reconoce el derecho de los niños al disfrute del más alto nivel posible de salud y al acceso a servicios para el tratamiento de las enfermedades. Dispone que para ello los Estados partes adoptarán las medidas apropiadas para asegurar la prestación de la asistencia médica que necesiten todos los niños, en especial la atención primaria en salud.

Adicionalmente, la Convención Iberoamericana sobre los Derechos de los Jóvenes, ${ }^{8}$ de la que Colombia no hace parte, establece en su artículo 25 que el derecho de los jóvenes a una salud integral y de calidad incluye la atención primaria gratuita, la educación preventiva, la promoción de la salud sexual, la nutrición, entre otros. Además, contempla el derecho de los jóvenes a la confidencialidad y al respeto del personal encargado de la prestación del servicio de salud, para lo cual los Estados parte deben adoptar y aplicar políticas y programas de salud especialmente orientados a ellos, en los que se incluya

$7 \quad$ Adoptada por la Asamblea General de las Naciones Unidas mediante Resolución 44/25, del 20 de noviembre de 1989. Entró en vigor el 2 de septiembre de 1990. Aprobada por Colombia mediante la Ley 12 de 1991.

8 Suscrita en octubre de 2005 por los Estados miembros de la Organización Iberoamericana de Juventud, organismo internacional de carácter multigubernamental, creado en 1992 para promover el diálogo, la concertación y la cooperación en materia de juventud entre los países iberoamericanos, uno de ellos Colombia. la prevención de enfermedades, la promoción de la salud y los estilos de vida saludable.

Hay que destacar que este instrumento internacional considera como "joven" a toda persona que se encuentre entre los 15 y 24 años de edad. $Y$ aplica para todos aquellos nacionales o residentes de los países que hacen parte de la Convención.

Una extensión especial de este acápite merecen los convenios de la ort, por la importancia que tienen en ellos los aspectos relativos al trabajo infantil. Las normas internacionales del trabajo son instrumentos jurídicos preparados por la oIT teniendo en cuenta tanto las perspectivas de los gobiernos como las de los empleadores y trabajadores. Estas normas se dividen en recomendaciones y convenios, entendidos estos últimos como tratados internacionales legalmente vinculantes ratificados por los Estados miembros. El Consejo de Administración de la oІт ha establecido que ocho convenios son "fundamentales". Estos abarcan temas que son considerados como principios y derechos fundamentales en el trabajo (oIt, s.f.), entre ellos se encuentran los Convenios 138 y 182, de los que se hablará a continuación.

En primer lugar está el Convenio $138^{9}$ sobre la edad mínima de admisión al empleo, según el cual, todo Miembro del Convenio "se compromete a seguir una política nacional que asegure la abolición efectiva del trabajo de los niños" (art. 1). La edad mínima "no deberá ser inferior

9 Aprobado por la Conferencia General de la olt, el 6 de junio de 1973, en Ginebra. 
a la edad en que cesa la obligación escolar, o en todo caso, a quince años" (art. 2, párr. 3). Dispone una excepción que aplica para aquellos miembros cuya economía y medios de educación estén insuficientemente desarrollados, consistente en que puedan especificar una edad mínima de catorce años (art. 2, párr. 4). Hay una disposición relativa a la salud del menor trabajador, contenida en el párr. 1 del artículo 3, según la cual "la edad mínima de admisión a todo tipo de empleo o trabajo que por su naturaleza o las condiciones en que se realice pueda resultar peligroso para la salud, la seguridad o la moralidad de los menores no deberá ser inferior a dieciocho años".

La legislación nacional, según el artículo 7 de la Convención, permite el empleo a personas de trece a quince años de edad, siempre y cuando sean trabajos ligeros. Se cataloga como trabajo ligero aquel no susceptible de perjudicar ni la salud o desarrollo del menor, ni su asistencia a la escuela, su participación en programas de orientación o formación profesional aprobados por la autoridad competente o el aprovechamiento de la enseñanza que reciben.

Finalmente, el Convenio $182^{10}$ relativo a las peores formas de trabajo infantil, establece en su artículo primero que todos los Estados Miembros deben adoptar "medidas inmediatas y eficaces para conseguir la prohibición y la eliminación de las peores formas de trabajo infantil con carácter de urgencia".

10 Aprobado por la Conferencia General de la Organización Internacional del Trabajo de la ort, el 17 de junio de 1999, en Ginebra.
En el artículo 3 lista lo que abarca la expresión "peores formas de trabajo infantil": todas las formas de esclavitud, la trata de niños, el reclutamiento de niños para ser usados en conflictos armados, la utilización de niños para la prostitución, la producción de pornografía, la utilización de niños para la realización de actividades ilícitas como el tráfico de estupefacientes, y en general, todo el trabajo que pueda dañar la salud, la moralidad o la seguridad de los niños.

Hay muchas normas en el marco internacional que a pesar de no tratar directamente el tema del derecho a la salud del joven trabajador, sí establecen unos contenidos mínimos de lo que este involucra y lo que significa la correcta prestación del servicio. Además, estas normas resaltan la protección especial de los derechos de los niños y todas las obligaciones que han adquirido los Estados en relación con la efectiva garantía del disfrute de sus derechos.

\section{REFLEXIÓN SOBRE LEGISLACIÓN NACIONAL Y SU COMPARACIÓN CON EL MARCO INTERNACIONAL}

En el derecho internacional no se encuentran muchas normas específicas relativas al derecho a la salud de los jóvenes trabajadores, y por lo general las que sí las contienen se refieren principalmente a los estándares bajo los cuales deberá regirse la prestación del servicio.

El primer gran avance en materia normativa en Colombia se encuentra contenido en el artículo 93 de la Constitución, según el cual prevalecen 
en el ordenamiento jurídico interno aquellos tratados y convenios internacionales ratificados por el Congreso sobre derechos humanos y que prohíben su limitación en los estados de excepción.

La Corte, en sentencia C-225 de 1995, al referirse al bloque de constitucionalidad manifestó que está compuesto por normas y principios que aún sin aparecer formalmente en el articulado del texto constitucional, son utilizados como parámetros del control de constitucionalidad de las leyes. Estos son verdaderos principios y reglas de valor constitucional a pesar de contener, en ocasiones, mecanismos de reforma diversos al de las normas del articulado constitucional en stricto sensu.

Posteriormente, la sentencia C-200 de 2002, con ponencia del magistrado Álvaro Tafur Galvis, establece que la revisión de constitucionalidad se debe hacer no solo sobre el texto formal de la Constitución, sino también frente a otras disposiciones a las cuales se les atribuye jerarquía constitucional. Se incluyen el bloque de constitucionalidad estricto sensu y otras normas que sin tener rango constitucional constituyen parámetros para el análisis de otras disposiciones, bloque de constitucionalidad lato sensu.

El segundo avance está en el inciso 4 del artículo 53 de la Constitución, y establece que los convenios internacionales de trabajo debidamente ratificados hacen parte de la legislación interna. La Corte Constitucional en la sentencia C-401 de 2005, en la cual se examinó la constitucionalidad del artículo 19 del Código Sustantivo del Trabajo, ratificó como tesis central que los convenios de la olt son normas aplicables de manera principal y directa. Adicionalmente, los convenios que integran el bloque de constitucionalidad en sentido estricto han de prevalecer en el orden interno según lo establecido en el inciso 1 del artículo 93 de la Constitución Política de Colombia, disposición que ha de ser reconocida y respetada (Ramírez, 2009, pág. 114).

En virtud de esta figura han entrado a la legislación colombiana vía leyes aprobatorias de tratados, entre otros, la Convención de Derechos del Niño (Ley 12 de 1991), el Convenio 138 de la оाт (Ley 515 de 1999), el Convenio 182 de la ort (Ley 704 de 2001) y el Pacto desc (Ley 74 de 1968).

Otro gran avance es el programa de la Defensoría del Pueblo, ProSeDHer, destinado a evaluar las políticas públicas desde una perspectiva de derechos humanos que integre los derechos económicos, sociales y culturales, e incidir en su diseño, implementación, ejecución y evaluación (Defensoría del Pueblo, s.f.).

La metodología usada por este programa tiene tres etapas: la primera consiste en identificar las problemáticas existentes frente a los derechos y sujetos; en la segunda se analizan las políticas públicas que el país ha puesto en marcha para dar cumplimiento a sus obligaciones en materia de derechos económicos, sociales y culturales; y en la tercera, a través de la elaboración de informes que brinden un análisis objetivo de un problema específico se plantea una serie de recomendaciones orientadas a asegurar la realización progresiva de los derechos que se estudiaron. El reto más importante que tiene 
la Defensoría del Pueblo en la implementación de este programa es lograr que las entidades encargadas del diseño y ejecución de las políticas públicas se familiaricen con la metodología, y hacer de este una guía para reformular las políticas públicas desde una perspectiva de derechos humanos (Defensoría del Pueblo, s.f.).

Es a partir de este punto que se encuentran las más graves falencias de la legislación colombiana en materia de salud de los jóvenes trabajadores, pues Colombia ha adquirido un número considerable de obligaciones internacionales sin adaptar su legislación para responder efectivamente a estas y garantizar su cumplimiento.

En primer lugar porque el Código Sustantivo del Trabajo, siendo la norma llamada a regular todo el tema del trabajo y las condiciones que lo rodean, no menciona lo relacionado con las personas que trabajan siendo menores de edad, y a pesar de haber sido reformado en múltiples ocasiones está desactualizado y no responde eficazmente a las condiciones laborales que se presentan actualmente en Colombia.

Particularmente en materia de salud, no hay una norma específica sobre cómo debe asumirse la afiliación y el pago de este servicio, así que debe regirse por lo que establece el Código Sustantivo, aunque todo lo relativo al trabajo infantil se encuentra en el Código de la Infancia y la Adolescencia. Esta dispersión innecesaria de normas dificulta su conocimiento y aplicación.

El único tema en el que se han visto esfuerzos normativos que en cierta medida responden a los compromisos internacionales adquiridos por Colombia es el de las peores formas de trabajo, regulado por la Resolución 1677 de 16 de mayo de 2008 y la Ley 679 de 2001, por medio de la cual se expide un estatuto para prevenir y contrarrestar la explotación, la pornografía y el turismo sexual con menores. Esto, en respuesta a lo establecido en el artículo 4 del Convenio 182 de la ort, según el cual la legislación nacional debe determinar cuáles son los tipos de trabajo que por su naturaleza o por las condiciones bajo las cuales se realiza puedan dañar la salud de los menores, para lo cual deberá consultar con las organizaciones de empleadores y las normas internacionales sobre la materia.

Lo cierto es que hay ausencia de reglamentación que promueva el cumplimiento de todos los compromisos adquiridos en materia de salud de los menores de edad a partir de la ratificación de tratados. Siendo los niños sujetos de especial protección por parte del Estado, hacen falta normas que impongan sanciones mucho más estrictas para los empleadores que se limitan a pagar los gastos médicos del menor solo en caso de que este llegue a enfermarse, y como consecuencia de no tenerlo afiliado al sistema de salud, pero sí cobran los incentivos tributarios por contratar menores en empleos dignos. Como se ha establecido en normas internacionales, el derecho a la salud no cubre solamente el tratamiento de enfermedades, sino que encierra una mayor cantidad de obligaciones para que el menor pueda obtener el más alto nivel de salud tanto física como mental. 


\section{CONCLUSIONES}

En Colombia existen disposiciones relativas al trabajo infantil y a la salud, pero muy pocas tratan específicamente el derecho a la salud de los jóvenes trabajadores. En especial, desde que se creó el bloque de constitucionalidad, nos encontramos ante un escenario que incluye algunas normas garantistas, pero que también deja ver grandes falencias.

Dentro de la normativa internacional, si bien no hay un enfoque específico del derecho a la salud de los jóvenes trabajadores, sí existen múltiples instrumentos que plantean unos estándares mínimos que el Estado debe garantizar a todos los niños y niñas.

El Estado adquiere compromisos internacionales por la ratificación de tratados y por el bloque de constitucionalidad, pero no hay reglamentación que promueva el cumplimiento de estas obligaciones. El mayor esfuerzo de Colombia se da en relación con los compromisos adquiridos al aprobar los Convenios de la ort.

Debido a que no hay un solo instrumento que condense todas las disposiciones relativas al derecho a la salud de los jóvenes trabajadores puede presentarse desconocimiento de la ley y se requiere la actualización normativa a nivel nacional.

En orden a suplir algunas faltas y lograr mayores avances se debe llenar el vacío respecto a las sanciones por no cumplir con algunas disposiciones 0 , incluso, crear incentivos tributarios para quienes las cumplan a cabalidad.
Hacen falta estudios que establezcan de manera general cuántos menores de edad están trabajando, en qué sectores, bajo qué condiciones y cuántos de ellos están vinculados al sistema de salud como cotizantes por tener un contrato de trabajo. Este desconocimiento impide que normativamente se pueda reaccionar de forma efectiva.

Finalmente, Colombia, aunque ha avanzado mucho en temas relacionados con la protección de los derechos humanos, tiene aún un largo camino por recorrer no solo en materia del derecho a la salud sino en general, para mejorar las condiciones de trabajo de los jóvenes trabajadores.

\section{Referencias}

Código de la Infancia y la Adolescencia. Ley 1098 de 2006.

Código Sustantivo del Trabajo. Decreto Ley 2663 del 5 de agosto de 1950. Diario Oficial, núm. 27.407, 9 de septiembre de 1950.

Congreso de la República de Colombia. (26 de diciembre de 1968). Ley 74 de 1968. Por la cual se aprueban los "Pactos Internacionales de Derechos Económicos, Sociales y Culturales, de Derechos Civiles y Políticos, así como el Protocolo Facultativo de este último, aprobados por la Asamblea General de las Naciones Unidas en votación unánime, en Nueva York, el 16 de diciembre de 1966".

Congreso de la República de Colombia. (22 de enero de 1991). Ley 12 de 1991. "Por medio 
de la cual se aprueba la Convención sobre los Derechos del Niño adoptada por la Asamblea General de las Naciones Unidas el 20 de noviembre de 1989".

Congreso de la República de Colombia. (21 de noviembre de 1992). Ley 704 de 2001. Por medio de la cual se aprueba el "Convenio 182 sobre la prohibición de las peores formas de trabajo infantil y la acción inmediata para su eliminación", adoptado por la Octogésima Séptima (87a.) reunión de la Conferencia General de la Organización Internacional del Trabajo, Ginebra, Suiza, diecisiete (17) de junio de mil novecientos noventa y nueve (1999).

Congreso de la República de Colombia. (23 de diciembre de 1993). Ley 100 de 1993. Por la cual se crea el sistema de seguridad social integral y se dictan otras disposiciones.

Congreso de la República de Colombia. (4 de agosto de 1999). Ley 515 de 1999. Por medio de la cual se aprueba el "Convenio 138 sobre la Edad Mínima de Admisión de Empleo", adoptada por la 58 ${ }^{a}$ Reunión de la Conferencia General de la Organización Internacional del Trabajo, Ginebra, Suiza, el veintiséis (26) de junio de mil novecientos setenta y tres (1973).

Congreso de la República de Colombia. (3 de agosto de 2001). Ley 679 de 2001. Por medio de la cual se expide un estatuto para prevenir y contrarrestar la explotación, la pornografía y el turismo sexual con menores, en desarrollo del artículo 44 de la Constitución.
Congreso de la República de Colombia. (8 de noviembre de 2006). Ley 1098 de 2006. Por la cual se expide el Código de la Infancia y la Adolescencia.

Constituyente. (1991). Constitución Política de Colombia. Recuperado de alcaldiabogota: http://www.alcaldiabogota.gov.co/sisjur/normas/Norma1.jsp?i=4125

Corte Constitucional de Colombia. Sentencia C-225 de 1995 (M. P.: Alejandro Martínez CabaIlero: mayo 18 de 1995).

Corte Constitucional de Colombia. Sentencia C-200 de 2002 (M. P.: Álvaro Tafur Galvis: marzo 19 de 2002).

Corte Constitucional de Colombia. Sentencia C-401 de 2005 (M. P.: Manuel José Cepeda Espinosa: abril 14 de 2005).

Corte Constitucional de Colombia. Sentencia T-760 de 2008 (M. P.: Manuel José Cepeda Espinosa: julio 31 de 2008).

Corte Constitucional de Colombia. Sentencia T-036 de 2013 (M. P.: Jorge Iván Palacio Palacio: enero 28 de 2013).

Corte Constitucional de Colombia. Sentencia T-133 de 2013. (M. P.: Jorge Iván Palacio: marzo 13 de 2013).

Corte Constitucional de Colombia. Sentencia T-218 de 2013 (M. P.: Alexei Julio Estrada: abril 17 de 2013). 
Defensoría del Pueblo. (s.f.). Programa de seguimiento y evaluación de políticas públicas en derechos humanos -ProSeDHer-. Recuperado el 30 de octubre de 2014, de Defensoría del Pueblo: http://www.defensoria.gov.co/es/public/ contenido/1307/ProSeDHer.htm

Departamento Administrativo Nacional de Estadística. (Agosto 23 de 2012). Encuesta Nacional de Trabajo Infantil 2011. [Comunicado de prensa]. Recuperado el 28 de octubre de 2014, de DANE: http://www.dane.gov.co/files/investigaciones/boletines/ech/jobinfantil/cp_trabinf_2011.pdf

Departamento Administrativo Nacional de Estadística. (Mayo 8 de 2014). Trabajo infantil. [Boletín de prensa]. Recuperado el 28 de octubre de 2014, de DANE: https://www.dane.gov.co/ files/investigaciones/boletines/ech/jobinfantil/ bol_trab_inf_2013.pdf

Fuentes Alcedo, C. I. (2006). Protegiendo el derecho a la salud en el Sistema Interamericano de Derechos Humanos: estudio comparativo sobre su justiciabilidad desde un punto de vista substantivo y procesal. Obtenido de digitalcommons: http://digitalcommons.wcl.american.edu/cgi/ viewcontent. cgi?article=1111\&context=auilr

Instituto Colombiano de Bienestar Familiar. (Junio 12 de 2013). ICBF ha atendido a 605 niños, niñas y adolescentes trabajadores en 2013. [Comunicado de prensa]. Recuperado el 30 de octubre de 2014, de ICBF: http://www.icbf.gov. co/portal/page/portal/Descargas1/Prensa1/ Tab/Lanzamiento-spea-sept2014.pdf
Instituto Colombiano de Bienestar Familiar. (Septiembre 23 de 2014). La prevención del embarazo adolescente requiere la acción conjunta de Estado, sociedad y familia. [Comunicado de prensa]. Recuperado el 30 de octubre de 2014, de ICBF: http://www.icbf.gov.co/portal/ page/portal/Descargas1/Prensa1/Lanzamiento-spea-sept2014.pdf

Maya, E. (2008). El derecho a la salud en perspectiva de derechos humanos y el sistema de inspección, vigilancia y control del Estado colombiano en materia de quejas en salud. Bogotá: Procuraduría General de la Nación.

Ministerio de la Protección Social. (Mayo 16 de 2008). Resolución 1677 de 16 de mayo de 2008. Por la cual se señalan las actividades consideradas como peores formas de trabajo infantil y se establece la clasificación de actividades peligrosas y condiciones de trabajo nocivas para la salud e integridad física o psicológica de las personas menores de 18 años de edad.

Ministerio de Trabajo. (2012). Sistema de Información Integrado para la identificación, registro y caracterización del trabajo infantil y sus peores formas (SIRITI). Obtenido de MINTRABAJo: http:// apps.mintrabajo.gov.co/siriti/display.aspx

Naciones Unidas. (1948). Declaración Universal de los Derechos Humanos. Adoptada mediante la Resolución 217 A (III) del 10 de diciembre de 1948 por la Asamblea General de la Organización de las Naciones Unidas. 
Naciones Unidas. (1959). Declaración de los Derechos del Niño. Aprobada por la Asamblea General de las Naciones Unidas mediante ResoIución 1386 (XIV) del 20 de noviembre de 1959.

Naciones Unidas. (1966). Pacto de Derechos, Económicos, Sociales y Culturales. Aprobado mediante la Resolución 2200 A (XXI) del 16 de diciembre de 1966 por la Asamblea General de la Organización de las Naciones Unidas.

Naciones Unidas. Comité de Derechos Económicos, Sociales y Culturales. (2000). Aplicación del Pacto Internacional de los Derechos Económicos, Sociales y Culturales, Observación general 14, El derecho al disfrute del más alto nivel posible de salud.

Organización de los Estados Americanos. (1948). Declaración Americana de los Derechos y Deberes del Hombre. Aprobada en la Novena Conferencia Internacional Americana. Bogotá, Colombia.

Organización Iberoamericana de Juventud. (Octubre de 2005). Convención Iberoamericana sobre los Derechos de los Jóvenes. Madrid: Secretaría General Iberoamericana/DESA/UNFPA.

Organización Internacional del Trabajo. (s.f.). Convenios y recomendaciones. Recuperado el 29 de agosto de 2014, de oाт: http://ilo.org/ global/standards/introduction-to-internationallabour-standards/conventions-and-recommendations/lang--es/index.htm

Organización Internacional del Trabajo. (1973). Convenio 138 de la ort. Sobre la edad mínima de admisión al empleo. Aprobado por la Conferencia General de la Organización Internacional del Trabajo de la oıт, el 6 de Junio 6, 1973

Organización Internacional del Trabajo. (1999). Convenio 182 de la ort. Sobre las peores formas de trabajo infantil. Aprobado por la Conferencia General de la Organización Internacional del Trabajo de la oIt, el 17 de junio 17 de 1999.

Organización Internacional del Trabajo. (2006). Reflexiones sobre la aplicación de los convenios de la olt sobre trabajo infantil y sus peores formas en América Central y República Dominicana. Obtenido de оाт: http://white.oit.org.pe/ ipec/documentos/jurisprudenciaparaweb.pdf

Organización Internacional del Trabajo. (2010). Trabajo decente y juventud en América Latina. Obtenido de ilo.org: http://www.ilo.org/wcmsp5/groups/public/---americas/---ro-lima/documents/publication/wcms_180132.pdf.

Organización Internacional del Trabajo. (Mayo de 2012). Resumen ejecutivo del informe "Tendencias mundiales del empleo juvenil 2012". Obtenido de ilo.org: http://www.ilo.org/wcmsp5/groups/public/---dgreports/---dcomm/documents/publication/wcms_181091.pdf

Organización Internacional del Trabajo. (2013). Medir los progresos en la lucha contra el trabajo infantil. Estimaciones y tendencias mundiales entre 2000 y 2012. Obtenido de ilo.org: http://www.ilo.org/wcmsp5/groups/public/--ed_norm/---ipec/documents/publication/ wcms_221514.pdf 
Pedraza Avella, A. C. y Ribero Medina, R. (2006). Presidencia de la República de Colombia. (30 El trabajo infantil y juvenil en Colombia y algu- de abril de 1998). Decreto 806 de 1998. Por el nas de sus consecuencias claves. Obtenido de revistaumanizales: http://revistaumanizales. cinde.org.co/index.php/Revista-Latinoamericana/article/viewFile/392/241 cual se reglamenta la afiliación al Régimen de Seguridad Social en Salud y la prestación de los beneficios del servicio público esencial de Seguridad Social en Salud y como servicio de interés

Presidencia de la República de Colombia. (29 de general, en todo el territorio nacional.

marzo de 1994). Decreto Reglamentario 692 de 1994. Por el cual se reglamenta parcialmente la Ley 100 de 1993.

Ramírez, M. F. (2009). Derecho Constitucional Colombiano. De la Carta de 1991 y sus reformas. Bogotá: Universidad del Rosario. 